\title{
Um percurso transcorrido na historiografia da linguística: sobre a história entrelaçada
}

\section{○ \\ OPEN ACCESS \\ EDITADO POR \\ - Gonçalo Fernandes (UTAD) \\ - Leonardo Ferreira Kaltner (UFF) \\ - Ronaldo Batista (UPM) \\ AVALIADO POR \\ - Sônia Nogueira \\ (UEMA SUL) \\ - Marcelo Rocha Gonçalves \\ (UFMS) \\ SOBRE OS AUTORES \\ - Neusa Barbosa Bastos \\ Conceptualização, \\ Investigação, Administração do Projeto, Supervisão, Escrita - \\ análise e edição. \\ - Nancy Casagrande \\ Conceptualização, \\ Investigação, Administração do Projeto, Supervisão, Escrita - \\ análise e edição.}

DATAS

- Recebido: 30/08/2021

- Aceito: 01/10/2021

- Publicado: 07/12/2021

\section{COMO CITAR}

Bastos, N. B.; Casagrande, N. (2021). Um percurso

transcorrido na historiografia da linguística: sobre a história

entrelaçada. Revista da Abralin, v. 20, n. 3, p. 511-521, 2021.

\author{
Neusa Barbosa BASTOS (D) \\ Pontifícia Universidade Católica de São Paulo (PUC-SP) \\ Universidade Presbiteriana Mackenzie (UPM) \\ Nancy CASAGRANDE @ \\ Pontifícia Universidade Católica de São Paulo (PUC-SP)
}

RESUMO

Objetivamos traçar o percurso transcorrido no Grupo de Pesquisas de Historiografia da Língua Portuguesa (GPeHLP /IPPUCSP), durante o período de 2004 a 2020, com foco no entrelaçamento da linguística com o ensino de língua materna nos últimos dezesseis anos, salientando que o Grupo se constituiu em 1996, com o estímulo da Prof ${ }^{a}$ Dr $^{a}$ Cristina Altman, introdutora da Historiografia no Brasil, que, na época, era a Coordenadora do GT Historiografia da Linguística Brasileira na ANPOLL. Procuramos sintetizar, desde o primeiro volume de 2004, os itens que foram sendo lapidados e nos guiaram na elaboração de todos os volumes até o de 2020, História entrelaçada 9: Língua Portuguesa na década de 1990: Linguística, Gramática, Redação e Educação, em que apontamos as linhas gerais de nosso trabalho, deixando pistas para o próximo livro que está em elaboração para ser publicado em 2022.

\section{ABSTRACT}

We aim at drawing a trajectory through Linguistic Historiography experienced by the Historiography Research Group in Portuguese Language (Grupo de Pesquisas de Historiografia da Língua Portuguesa (GPeHLP/IPPUCSP), at Pontifícia Universidade Católica de São Paulo, from 2004 to 2020 , focusing on the intertwining of Linguistics with the teaching of the 


\section{REVISTA DA ABRALIN}

native language; it is relevant to underline that the Group was created in 1996, encouraged by Dr. Cristina Altman who introduced Linguistic Historiography in Brazil, and at the time was the coordinator of the GT Historiografia da Linguística Brasileira, ANPOLL. We attempted to sum up, from the very first 2004 volume, the items that were being developed and guided us in the forthcoming publications till 2020: Intertwined History 9: Portuguese Language in the 1990 decade: Linguistics, Grammar, Writing and Education (História entrelaçada 9: Língua Portuguesa na década de 1990: Linguística, Gramática, Redação e Educação), in which we indicated the general lines of our studies, pointing the main elements for the next book we have been working on to be published in 2022 .

\section{PALAVRAS-CHAVE}

Historiografia linguística. História Entrelaçada. Ensino de Língua Portuguesa.

\section{KEYWORDS}

Linguistic Historiography. Intertwining Linguistics. Portuguese Language Teaching.

\section{Introdução}

Objetivamos, neste artigo, traçar o percurso transcorrido no Grupo de Pesquisas de Historiografia da Língua Portuguesa (GPeHLP/IPPUCSP), durante o período de 2004 a 2020, com foco no entrelaçamento da linguística com o ensino de língua materna nos últimos dezesseis anos, salientando que o Grupo se constituiu em 1996, com o estímulo da Prof ${ }^{a}$ Dr $^{\text {a }}$ Cristina Altman, introdutora da His toriografia no Brasil, que, na época, era a Coordenadora do GT Historiografia da Linguística Brasileira na ANPOLL.

O panorama começa a ser traçado a partir da concepção de Historiografia Linguística que se adotou desde 2002, estando vinculada à concepção de História, em sentido amplo, como forma de registro dos feitos históricos. Lembramos que o nascimento da Historiografia se deu na França, também vinculada à História, como ciência, passando por um processo de adaptação aos paradigmas que nortearam os estudos históricos e historiográficos. Deixando de se resumir a História à narrativa dos acontecimentos, a Historiografia tinha como papel fundamental o registro desses acontecimentos problematizando-os ou questionando-os. Era a vigência do paradigma da ciência normal que "(...) não tem como objetivo trazer à tona novas espécies de fenômeno; na verdade aqueles que não se ajustam aos limites do paradigma frequentemente nem são vistos (...) Kuhn (1997, p.45).” 


\section{REVISTA DA ABRALIN}

Sendo assim, é preciso considerarmos que tais fenômenos, aos quais se refere Kuhn, acabam por suscitar novas rupturas no paradigma vigente, pois se, num primeiro momento, eles não são considerados, num segundo instante, passam a ser os responsáveis pelo nascimento de novas visões na ciência. Nesse caso, é importante levarmos em conta as várias rupturas pelas quais a História, na qualidade de ciência, passou. A primeira delas ocorreu quando essa ciência deixou de ser encarada como mero relato de acontecimentos, para estabelecer-se, como uma procura das ações realizadas pelo homem, instituindo como seu objeto as ações humanas.

É importante ressaltar que, no campo historiográfico, a maior contribuição, na busca de um novo método, é dada por Lucien Febvre, Marc Bloch, Ferdinand Braudel, na primeira metade do século XX, com a fundação da revista Annales (1929), cujo objetivo maior era o de promover um novo tipo de História e, certamente, de Historiografia. Com essa mudança de paradigma caracterizou-se como a "revolução francesa da Historiografia", uma vez que impôs uma nova visão de registro histórico.

Nessa perspectiva científica, a Historiografia institui-se como método interdisciplinar, pelo fato de considerar a colaboração de outras disciplinas, quais sejam: a Sociologia, a Psicologia, a Economia, a Geografia e a Linguística, revelando-se, assim, a intenção de registrar os feitos humanos em sua totalidade.

\section{Sobre a Historiografia Linguística (HL)}

Visto que nosso interesse está centrado em compreender a Historiografia Linguística (HL), passaremos, então, a apresentar as acepções do termo. Para isso, basear-nos-emos nas palavras de Koerner (1996, p. 45) quando diz da necessidade de compreendermos a HL como "modo de escrever a história do estudo da linguagem baseado em princípios científicos" e não mais como mero registro da história da pesquisa linguística. Sabemos que essa nova concepção requer um olhar mais cuidadoso por parte do historiógrafo, que se diferenciará do olhar do historiador a partir do momento em que a HL se estabelece como disciplina.

Para que isso de fato aconteça, é preciso recuperar o passado linguístico que se apresenta como parte integral da disciplina, inclusive no que diz respeito à Linguística como ciência, não descartando sua influência em outras ciências como a Psicologia, a Sociologia e a Ciência Política. Tal natureza interdisciplinar requer do investigador um conhecimento amplo dos diversos campos científicos, pois seu campo de investigação deveria comportar vieses que, segundo Koerner (1996, p. 47), consistiriam em

(...) favorecer o restabelecimento dos fatos mais importantes do nosso passado linguístico 'sine ira et studio' e explicar, tanto quanto possível, as razões da mudança de orientação e de ênfase e a possível descontinuidade que delas se pode observar, sua prática requer, ainda, capacidade de síntese, isto é, a faculdade de destilar o essencial da massa dos fatos empíricos coligidos a partir de fontes primárias. 


\section{REVISTA DA ABRALIN}

Nesse sentido, tem início a discussão sobre a tarefa do historiador e a do historiógrafo sendo delegadas a cada um obrigações que interferem na instauração da HL como disciplina. O historiador deverá, então, investigar as reivindicações através de uma pesquisa empírica, distinguindo entre elas as que estão sendo feitas e os êxitos atuais, olhando, ainda, os fatos que podem ter desempenhado um papel significativo no estabelecimento de novos compromissos. Isso significa que lhe cabe descrever o processo e a atmosfera de uma 'revolução' em curso.

O historiógrafo, por sua vez, deverá trazer essas descobertas empíricas para a perspectiva correta, interpretá-las e oferecer uma explicação adequada dos fatos. Sendo assim, sua tarefa é a de estabelecer princípios que guiem o historiador. Esses princípios estariam voltados à compreensão do clima de opinião do período e a sua avaliação particular do objeto de estudo. Para tanto, tais princípios exigem que o historiógrafo da linguística seja dotado de um conhecimento tão amplo que possa não só ter o domínio específico sobre o seu campo de investigação, mas também o domínio sobre a história geral.

Nesse aspecto, as considerações de Collingwood (in KOERNER, 1974) são primordiais, já que esse estudioso faz uma importante distinção entre a crônica e a história, definindo os limites e as diferenças entre História e Historiografia. Sendo assim, a Historiografia não seria mera coleta de "dados orientados", mas estaria relacionada a uma "teoria orientada", "embora não haja dúvida de que muita leitura das fontes originais ainda tenha que ser feita, a fim de estabelecer adequadamente os fatos básicos no desenvolvimento da disciplina". (KOERNER, 1996, p. 47).

A partir dessa afirmação, podemos dizer que a busca pelo estabelecimento da Historiografia como disciplina vem da década de 70. Nesse período, a obra de Kuhn - A Estrutura das Revoluções Científicas - instaurou-se como marco na compreensão das revoluções científicas, pois, ao abordar a questão relativa à mudança de paradigmas na ciência, o autor suscitou a comunidade científica, ligada à linguística, a buscar seus paradigmas.

\section{Sobre a metodologia em HL}

A busca a de uma metodologia para a disciplina HL depende de inúmeros estudos dos investigadores da área que devem considerar, inclusive, o estabelecimento da Linguística como ciência. Podemos afirmar que inúmeros têm sido os caminhos percorridos pela Linguística no Brasil, na última década, entretanto, a nós interessa, em especial, o da Historiografia, que estabelecida como disciplina, a (HL) tem como objeto de estudos a seleção, a ordenação e a reconstrução do conhecimento linguístico baseado em interpretações críticas do processo dessa produção contextualizada do ponto de vista histórico, social e cultural. De Clerq e Swiggers (1991) afirmam que a HL pode ser definida como estudo do saber linguístico que tem como objetivo descrever e explicar como se adquiriu, produziu e desenvolveu o conhecimento linguístico em um determinado contexto.

Nesse sentido, a HL instaura-se como disciplina explicativa, visto que busca abordar questões que estejam além da dimensão do conhecimento acerca da linguagem, relacionando-se com o papel 


\section{REVISTA DA ABRALIN}

dos agentes no desenvolvimento do conhecimento e a dimensão social que identifica o contexto e suas influências sobre o conhecimento linguístico.

São objetos da HL não só os textos publicados, mas também os não publicados - fontes complementares de pesquisa - que estejam ligados à visão do interlocutor, reconhecendo que o conhecimento linguístico é construído pela interação dinâmica entre aqueles que concordam ou discordam de um dado conhecimento, inseridos num contexto histórico. É fato importante ressaltarmos que correspondências, cartas, rascunhos ou qualquer documento pessoal produzido por uma comunidade científica será objeto da HL, constituindo-se como fonte primária de pesquisa, fonte original da informação a ser discutida e estabelecendo-se como fontes secundárias, todos os documentos que relacionam ou discutem informações originalmente apresentadas em outros registros.

A partir de nossas primeiras considerações sobre o conceito de HL, passaremos às questões da busca do método que perduram até nossos dias, devendo apontar as recentes pesquisas de Koerner (2014, 2020), Swiggers (2010), Altman (1998, 2019), Batista (2021), Batista e Bastos (2020) que alimentam nosso grupo em nossas publicações contemporâneas.

Buscamos em Altman (1998, p. 24) a definição da atividade historiográfica, em que apresenta um primeiro movimento metodológico, a atividade de seleção, ordenação, reconstrução e interpretação:

A atividade historiográfica que ambiciona compreender os movimentos em história da ciência, presume, inevitavelmente, uma atividade de seleção, ordenação, reconstrução e interpretação dos fatos relevantes (história 'rerum gestarum') para o quadro de reflexão que constrói o historiógrafo.

Considerando a HL como "estudo do saber linguístico", passou-se a questionar a inclusão e a exclusão dos objetos de estudos da HL para que se possa, enfim, definir seus limites. Tarefa complexa que necessita dos documentos já publicados, dos testemunhos escritos ou de gravações em áudio e vídeo. Cabe ao historiógrafo buscar os documentos que fazem parte desse conjunto, quais sejam: a correspondência entre linguistas e as entrevistas dadas a pesquisadores. Ambas poderão constituir fontes primárias de consulta para o pesquisador interessado em reconstruir uma outra História da Linguística.

É importante ressaltar o fato de que os historiógrafos da linguística devem constituir um "corpus" de valor historiográfico, cuja documentação inserida num contexto, o clima intelectual da época, são fatores relevantes para a constituição de uma atividade historiográfica que pode ter um caráter metalinguístico, focando obras gramaticais, dicionários, materiais didáticos e não metalinguístico, focalizando a correspondência, as notas ou até mesmo a documentação reunida por estudiosos (que dificilmente divulgam como ou em que circunstâncias chegam a determinados resultados de pesquisa). Consideremos, ainda que além do objeto de investigação pode ser considerado metalinguístico, pode também ser não metalinguístico. Dessa maneira, repetindo, um objeto metalinguístico constitui-se de gramáticas, manuais didáticos, antologias etc. e, em se considerando um objeto não-metalinguístico temos leis, cartas, documentos oficiais etc.

Para refletir sobre esses aspectos, é preciso que levemos em conta o fator subjetividade da HL, pois é necessário voltar as atenções para o sujeito da historiografia, implicando o contexto científico 


\section{REVISTA DA ABRALIN}

e cultural, a motivação, a formação profissional, as convicções científicas e ideológicas, a metodologia e, enfim, o estilo do historiador.

Deve-se considerar, nos estudos historiográficos, as ciências sociais, embora não possam elas servir de guias para uma metodologia de análise na área. Sobre isso afirma Koerner (1996, pp. 56-57):

(...) De fato, em última análise, os historiadores da ciência lingüística terão de desenvolver seu próprio quadro de trabalho, tanto o metodológico, quanto o filosófico. Para isto, um conhecimento meticuloso de teoria e da prática em outros campos revelam-se verdadeiramente muito úteis, mesmo se o resultado for negativo, isto é, se o historiador da lingüística descobrir que este ou aquele campo de investigação histórica tem de fato pouco a oferecer em matéria de método historiográfico. (...).

A partir dessa afirmação, podemos concluir que a HL não tem ainda um método plenamente instituído. Por esse motivo, não havendo um quadro metodológico para a HL, que possa ser obtido das ciências sociais, resta ao historiógrafo buscar seus próprios caminhos para a sua constituição, considerando sempre a influência, seja mais exata, seja mais abstrata, de outras disciplinas no desenvolvimento tanto da HL, quanto de qualquer outra área de estudos, busca essa que tem sido constante, como mencionamos acima.

Essa busca de caminhos próprios requer do historiógrafo, segundo De Clerq e Swiggers (1991) motivações que, ao longo da história da HL, seriam fundamentadas em cinco tipos:

1. motivação de fazer a HL como sujeito enciclopédico, como "ramo" de uma enciclopédia do saber;

2. motivação de fazer HL como ilustração do progresso de conhecimento;

3. motivação de fazer a HL com o objetivo de defender, difundir ou promover um modelo linguístico particular em detrimento de outros;

4. motivação de fazer a HL como descrição e explicação de conteúdos de doutrina, inserida em um contexto histórico e científico;

5. motivação de fazer a HL como testemunha exterior sobre uma realidade social, "colorida" pelas concepções e práticas linguísticas. Muitas são as motivações e temos com elas construído nossos estudos historiográficos.

Merece nossa atenção, ainda dentro da busca de um método historiográfico, as relações de continuidade e de descontinuidade na HL. Para tanto, torna-se relevante ressaltar que Kuhn serviu como ponto de referência para a compreensão das ditas continuidades e descontinuidades no processo de evolução das ciências. Nesse sentido, Altman (1998, p. 27) afirma que, 


\section{REVISTA DA ABRALIN}

na visão kuhniana de progresso científico, cada nova etapa de evolução implica ruptura - de teorias, métodos, seleção de problemas e critérios de solução de problemas - com o conhecimento anterior. Ao invés de somente continuidade e acumulação, haveria, de tempos em tempos, períodos de descontinuidade e ruptura responsáveis pela formação de um novo 'paradigma', incomparável e incomensurável em relação ao que o precedeu.

Como historiógrafos, cumpre reconstruir as práticas linguísticas de um determinado momento histórico, rastreando sua continuidade e sua ruptura ao longo do tempo, quanto às concepções filosóficas e científicas sobre a educação e o ensino de língua, imbuídos de uma política linguística, que teve início no século XVI, em Portugal, e desenrolou-se até o século XIX, em Portugal e no Brasil, enfatizando as publicações brasileira a partir do século XIX.

Para tanto, convém retomar que perscrutamos o clima de opinião em cada período em Portugal e no Brasil, estabelecendo em nosso trabalho o objetivo de fazer uma Historiografia da Linguística, voltada para o entrelaçamento entre a Linguística e o Ensino de Línguas, mais precisamente, o ensino de Língua Portuguesa, ao longo de 400 anos, em fontes primárias, as gramáticas do português e os materiais didáticos publicados em Portugal e no Brasil, no período mencionado, traçando um percurso da formalização do Ensino de Língua Portuguesa, nos dois países, na escola vista como instituição de poder.

Podemos elencar fatores importantes que contribuíram com o nosso trabalho historiográfico, os quais apresentaremos como passos a serem dados pelo historiógrafo. A delimitação do campo de trabalho, a colocação do problema central, que consiste em um olhar explicativo sobre a relação entre o ensino de Língua Portuguesa e as gramáticas e materiais didáticos do Português, vistos em sua organização e as adequações sofridas através dos tempos por interferências externas e/ou internas, observando como interferência externa concernente à problematização do objeto de estudo, à seleção do material, à reconstrução histórica e epistemológica dos fatos e examinando a interferência interna, atinente às relações da língua com o passado, às considerações acerca do conhecimento adquirido de maneira a avançar e ir além de simples considerações.

Examinando o modo de escrever a história do saber linguístico, tendo como objetivo descrever/ explicar como se desenvolveu tal saber em um determinado contexto, desembocamos não só na análise de um produto acabado dentro de um recorte no tempo, mas também na consideração de seus mecanismos geradores, afinal, uma obra será sempre explicada mais profundamente quando, nela, percebemos as etapas de conhecimento que a engendraram em grupos de especialidade. Trata-se das influências exercidas por um grupo de especialidade que interfere em produções subsequentes.

Dando continuidade aos pontos fundamentais vistos como procedimentos metodológicos na elaboração do livro, elencaremos quatro pontos: passos investigativos; questão das fontes; princípios koerneanos; dimensões/parâmetros.

Os passos investigativos abrangem quatro momentos: seleção, ordenação, reconstrução e interpretação. Sendo que, no primeiro momento, selecionam-se os documentos gramaticais a serem estudados dentre todos os que houver, elegendo os mais representativos relacionados ao objetivo do historiógrafo. No segundo momento, havendo mais de um documento no período, imprime-se uma ordem cronológica. Em nosso caso particular, uma vez que pretendíamos estabelecer um percurso das 


\section{REVISTA DA ABRALIN}

gramáticas e dos materiais didáticos da Língua Portuguesa, numa perspectiva historiográfica, enfocamos os posicionamentos linguístico-pedagógicos constantes das obras e as implicações socioculturais referentes aos diversos momentos históricos. No terceiro momento, reconstrói-se o conhecimento linguístico dos vários recortes temporais considerados, baseando-nos, por fim, na interpretação crítica do processo dessa produção contextualizada a partir do clima de opinião delineado.

A questão das fontes, que podem ser primárias e secundárias, deve ser observada com cuidado. Inicialmente, como todos os historiadores, exploram-se as fontes primárias (documentos originais), para delas extrair elementos que permitiram dar, seguramente, os passos investigativos. Depois se lança mão das fontes secundárias, ou seja, aquelas que (às vezes escassas) permitem verificar o que já foi estudado sobre os documentos que se tem em mãos.

Os princípios básicos koerneanos que propõem que o historiógrafo, como qualquer outro cientista, não trabalha sem princípios que o norteiem, visando à credibilidade de sua pesquisa: 1. contextualização (as mais variadas correntes filosóficas, políticas, econômicas, cientificas e artísticas que, ao se interinfuenciarem, marcam indelevelmente todo um determinado período histórico, e dentro dele, portanto, o pensamento linguístico e a sociedade em geral. Isso nos impele a recorrer ao "clima de opinião" cultural da época em que determinado pensamento se desenvolveu; clima formado pelo endosso e pelo abandono de valores, a partir da revisão de paradigmas.

Em seguida, 2. imanência (o esforço do historiógrafo de entender o texto linguístico produzido, histórica e criticamente, e filologicamente se possível. Entretanto, tal atitude não poderá desviá-lo da fidelidade as que foi dito, ou seja, cabe-lhe respeitar não só o quadro geral da teoria em questão, como também as acepções terminológicas definidas internamente, e não em referência à doutrina linguística moderna, qualquer que seja a linha teórica que o embase e 3. adequação (a obediência aos dois primeiros. Diz respeito ao momento de o historiógrafo, de forma implícita, aventura-se a introduzir aproximações modernas do vocabulário técnico e a construir um quadro conceitual de trabalho que permita, à apreciação dos textos analisados, seus conceitos e teorias, com a constatação das afinidades de significado que subjazem a ambas as definições).

O quarto momento refere-se às dimensões cognitiva e social, vistas como internas, por incluirse nos recortes espaço-temporais determinados, buscando, amplamente, as linhas teóricas e/ ou metodológicas que a orientaram e como externa, explorando os aspectos sociais com relação aos grupos de estudiosos em questão. Tais dimensões/parâmetros internos e externos em relação ao campo de trabalho dos historiógrafos, é assim tratado por Bastos (2020, p. 115)

\footnotetext{
é tudo o que se passou no campo da linguagem, observado a partir de procedimentos teórico-metodológicos da historiografia linguística, voltando-se para a descrição e explicação dos conhecimentos linguísticos produzidos pelo homem, pois ao descrevermos e explicarmos como se produziu e desenvolveu tal conhecimento linguístico num período determinado, estamos implicados com as dimensões externas (sociais) e internas (cognitivas) em um determinado contexto social e cultural, visando a estabelecer o conhecimento científico em nossa área de estudo.
}

Claro está que as etapas metodológicas aqui enumeradas, fazendo-nos supor certa ordem, não são rigidamente estanques, cabendo ao historiógrafo decidir-se quando aos seus procedimentos 


\section{REVISTA DA ABRALIN}

teórico metodológicos. Afinal, cada pesquisador parte de algumas perguntas problematizadoras para o encaminhamento de seu trabalho. Como por exemplo: Quem são os estudiosos da ciência da língua selecionados? O que é gramática para eles? O que pensam sobre o ensino de Português? Em que medida adotaram em suas obras os conhecimentos acatados na época, ou deles se afastaram pela crença em valores diferenciados? Qual o grau de representatividade das obras na época e além dela? Que contribuição deixaram, a ponto de, hoje, analisarmos suas gramáticas e seus materiais didáticos com vistas à Historiografia Linguística?

\section{Resultados e Discussões}

Há questões importantes que mereceram ponderações do GPeHLP, por estarmos adentrando no século XX observando a necessidade de tecer considerações importantes sobre objetos de estudo contemporâneos, a saber: Como ficaria o princípio da adequação? Ele seria dispensável? Haveria um processo cumulativo no qual imanência e adequação se sobreporiam?

De acordo com Bastos e Palma (2008), sobre essas questões, algumas reflexões foram feitas com base no que propõe Tétart (2000). Convém destacar, inicialmente, que a história do tempo presente não é uma novidade, pois ela já foi desenvolvida na Grécia, por meio do trabalho de Tucídides. Sofreu, entretanto, muitas críticas como as de Jacques Le Goff (1978, apud Tétart 2000) que considerava que ela devesse ser realizada por jornalistas ou politólogos e não por historiadores. Foram os estudos sobre a Segunda Guerra Mundial que abriram campo para trabalhos dessa natureza, uma vez que se considera o tempo presente como um campo histórico repleto de discursos científicos, pedagógicos, linguísticos advindos de movimentos intelectuais, científicos e de demandas sociais.

O historiógrafo do tempo presente com o objetivo de assegurar o rigor científico de sua pesquisa, deve ter clareza, para proceder à investigação, acerca de seus critérios, de seu método, das fontes disponíveis e das posições que deve adotar em relação à história da qual participou, procurando preservar um distanciamento frente à análise de documentos que focalizam fatos dos quais, muitas vezes, o pesquisador foi testemunha e deve manter-se imparcial no seu julgamento, destacando-se a impossibilidade de uma "pura objetividade". Nesse sentido, encontramos o dito de Tétart (2000, p.136, in Bastos e Palma, 2008, p. 13):

Ele (o historiador dos tempos presentes) recusa, contudo, a doxa que afirma que só se fala com razão do passado morto. Nenhum passado morre, pois, inerva continuamente a história dos indivíduos. De resto, conhecendo a especificidade de seu trabalho, ele deve, talvez mais do que qualquer outro, escrever com consciência e rigor, perseguindo sempre a parte de ego-história em sua maneira de decifrar e dizer o passado.

E continuamos caminhando, ao examinarmos a possibilidade de estudo historiográfico de obras do tempo presente suscita algumas perguntas: 1. como seria aplicado o princípio da adequação? Quanto a essa indagação duas respostas são possíveis de acordo com Bastos e Palma (2008, p. 14): 


\title{
REVISTA DA ABRALIN
}

\begin{abstract}
A primeira levando em conta que o objeto de estudo seja metalinguístico e a teoria que o embasa seja atual, então não haveria necessidade de confrontá-la com outra teoria do mesmo período. No caso de um objeto de estudo não metalinguístico, dada a sua contemporaneidade, a teoria que fundamenta o princípio da imanência deve ser concomitante temporalmente ao documento sob análise, logo também não seria necessária a adequação teórica, como um procedimento metodológico separado, uma vez que se julga que o leitor tenha familiaridade com os fundamentos teóricos utilizados. Essas situações indicam um processo cumulativo em que o princípio da imanência e o da adequação seriam aplicados ao mesmo tempo, com base no mesmo arcabouço teórico.

A segunda resposta possível prevê a aplicação do princípio da adequação. Nesse caso, o objetivo seria estabelecer relações entre duas teorias que convivem no mesmo clima de opinião, apontando-se as convergências e as divergências entre elas, possibilitando, assim, ampliar a visão crítica do documento pelas relações teóricas estabelecidas.
\end{abstract}

Saliente-se a concepção de Batista (2020, p. 38) na qual para a atividade historiográfica acrescenta que se deve compreender:

(...) que a elaboração de uma narrativa historiográfica é circunscrita a seu momento histórico e aos objetivos do historiador/historiógrafo. Essa perspectiva implica ressaltar o caráter de narratividade de uma análise e de um texto histórico, produtos da seleção e da interpretação de um historiador que operou recortes e definiu parâmetros de análise.

Uma atividade historiográfica, portanto, que precisa ser compreendida em meio ao discursivo da produção intelectual (resultante de um ponto de vista) e à necessidade de critérios metodológicos de observação que garantam a natureza cientifica e não enviesadamente pessoal de uma interpretação sobre eventos da história.

\section{Conclusão}

Para finalizar, sintetizamos itens, de acordo com Bastos e Palma, 2020, p. 8-9, que foram sendo lapidados desde o nosso primeiro volume de 2004 que nos guiaram na elaboração do História entrelaçada 9: Língua Portuguesa na década de 1990: Linguística, Gramática, Redação e Educação, em que apontamos as linhas gerais de nosso trabalho no volume de 2020, a ser publicado em 2022, para as análises do material didático:

\footnotetext{
I) Concepções de linguagem e o ensino da Língua Portuguesa, sob as seguintes perspectivas científica (recorte do conteúdo da teoria para constituir tópico de uma disciplina curricular?) política (pressupostos ideológicos que levam a instituir um certo conteúdo em disciplina curricular e que subjazem aos objetivos e procedimentos de ensino dessa disciplina); sociocultural: (a) condições de produção e recepção de determinado conhecimento, no âmbito escolar; b) imagens desses agentes do processo e do conteúdo curricular) e visão histórica (reconstrução dos processos, por meio dos quais determinado conhecimento foi se configurando como saber escolar.

II) Concepções de linguagem subjacentes a propostas pedagógicas da década de 1990.
}

Atentos aos avanços dos estudos da HL, sabemos estar na direção certa, uma vez que, de 1996 até 2021, continuamos a caminhar com adeptos de todas as partes do Brasil, ampliando e divulgando 


\section{REVISTA DA ABRALIN}

nosso trabalho entre seus pares, formando pesquisadores jovens que, movidos pelo amor à pesquisa pelos estudos linguísticos, vem traçando um percurso historiográfico, por meio do trabalho de nossos grandes estudiosos. Assim, esperamos ter deixado uma contribuição aos estudos da HL, estando abertos para as críticas e discussões profícuas.

\section{REFERÊNCIAS}

ALTMAN, C. A pesquisa lingüística no Brasil (1968-1988). São Paulo: Humanitas/FFLCH/USP, 1998.

ALTMAN, C. História, Estórias e Historiografia da Linguística Brasileira. In: Batista, Ronaldo de Oliveira (Org.).

Historiografia da Linguística. São Paulo: Contexto, 2019. p. 9-43.

BASTOS, N. B. e PALMA, D. V. (orgs.). História Entrelaçada: a construção de gramáticas e o ensino de língua portuguesa do século XVI ao XIX. 1. ed. Rio de Janeiro - RJ: Lucerna, 2004.

BASTOS, N. B. e PALMA, D. V. (orgs.) História Entrelaçada 2 - a construção de gramáticas e o ensino de língua portuguesa o século XIX. Rio de Janeiro: Nova Fronteira - IP-PUC/SP - Lucerna, 2006.

BASTOS, N. B. e PALMA, D. V. (orgs.). História Entrelaçada 9: Língua Portuguesa na Década de 1990: Linguística, Gramática, Redação e Educação. São Paulo: Pá de Palavras, 2020.

BATISTA, R. de O. História e Historiografia da Linguística: mapa de orientação. In BATISTA, R. de O. e BASTOS, N. B. (orgs.) Questões em historiografia da linguística - homenagem à Cristina Altman. Pá de Palavras: São Paulo, 2020.

BATISTA, R. de O (org.). Historiografia da Linguística. São Paulo: Contexto, 2019.

DE CLERQ, J. SWIGGERS, P. L'Histoire de la Linguistique: L'autre Histoire et L'Histoire d'une Histoire. Neue fragen der Linguistik .org. por Elizabeth Felbusch, Reiner Pogarell e Cornelia Weiss. Tübingen: Verlag, 1991.

KOERNER, E. F. K. Questões que persistem em Historiografia Linguística. Revista da ANPOLL, nº 2, pp. 45-70, 1996

KOERNER, E. F. K. Quatro décadas de historiografia linguística: estudos selecionados. Seleção e edição de textos de Rolf Kemmler e Cristina Altman. Coleção Linguística 11, Centro de Estudos em Letras - Universidade de Trás-os -Montes e Alto Douro. Vila Real, 2014.

KOERNER, E. F. K. Last Papers Linguistic Historiography. In Studies in History of the Language Sciences 128. Amsterdam/Philadelphia: John Benjamins Publishing Company, 2020.

KUHN, T. S. A estrutura das revoluções científicas. 5. ed. São Paulo: Editora Perspectiva S.A, 1997.

SWIGGERS, P. La historiografía de la lingüística: apuntes y reflexiones. Revista argentina de historiografía lingüística, I, 1, 67-76, 2009.

SWIGGERS, P. Historiographia Lingüística in Terra Brasiliensis: um depoimento de Leuven para o Brasil. In BASTOS, N. B. e BATISTA, R. de O. (orgs) Questões em historiografia da linguística - homenagem à Cristina Altman. Pá de Palavras: São Paulo, 2020.

TÉTART, P. Pequena História dos historiadores. (tradução Maria Leonor Loureiro). Bauru, SP: EDUSC, 2000. 